\title{
Asbestos is Still with Us: Repeat Call for a Universal Ban
}

\author{
Collegium Ramazzini ${ }^{\dagger}$
}

Collegium Ramazzni International Headquarters, Castello dei Pio, 41012 Carpi/Modena, Italy

General Secretariat, Castello di Bentivoglio, 40010 Bentivoglio, Bologna, Italy

(Received March 11, 2010/Revised March 28, 2010/Accepted April 15, 2010)

\begin{abstract}
All forms of asbestos are proven human carcinogens. All forms of asbestos cause malignant mesothelioma, lung, laryngeal, and ovarian cancers, and may cause gastrointestinal and other cancers. No exposure to asbestos is without risk, and there is no safe threshold of exposure to asbestos. Asbestos cancer victims die painful lingering deaths. These deaths are almost entirely preventable. When evidence of the carcinogenicity of asbestos became incontrovertible, concerned parties, including the Collegium Ramazzini, called for a universal ban on the mining, manufacture and use of asbestos in all countries around the world. ${ }^{1)}$ Asbestos is now banned in 52 countries, and safer products have replaced many materials that once were made with asbestos. Nonetheless, a large number of countries still use, import, and export asbestos and asbestos-containing products. And still today in many countries that have banned other forms of asbestos, the so-called "controlled use" of chrysotile asbestos continues to be permitted, an exemption that has no basis in medical science but rather reflects the political and economic influence of the asbestos mining and manufacturing industry. To protect the health of all people in the world - industrial workers, construction workers, women and children, now and in future generations - the Collegium Ramazzini calls again today on all countries of the world, as we have repeatedly in the past, to join in the international endeavor to ban all forms of asbestos. An international ban on asbestos is urgently needed.
\end{abstract}

Keywords: asbestos, asbestosis, asbestos-related diseases, ban, cancer, chrysotile

\section{Background}

Asbestos is a term applied to six naturally occurring fibrous minerals. These minerals occur in two configurations: serpentine and amphibole. The only type of asbestos derived from serpentine minerals, chrysotile, also known as white asbestos, accounts for 95 percent of the asbestos ever used around the world, and it is the only type of asbestos in commercial use today. Amphibole minerals include five asbestos species: amosite, crocidolite, tremolite, anthophyllite, and actinolite. The two forms of amphibole asbestos that previously were most commercially important-amosite, or brown asbestos, and crocidolite, or blue asbestos--are no longer in use.

Corresponding author: Collegium Ramazzni International Headquarters, Castello dei Pio 41012 Carpi/Modena, Italy Tel: 39-051-6640650

E-mail: collegium@ramazzini.it
Asbestos fibers can withstand fire, heat and acid. They have great tensile strength. They provide thermal insulation and acoustic insulation. For these reasons, asbestos came into wide commercial use and gave rise to a burgeoning industry many years before its detrimental health effects, which often take years to appear, became known.

All forms of asbestos cause asbestosis, a progressive, debilitating fibrotic disease of the lungs. All forms of asbestos cause human cancer. All forms of asbestos cause malignant mesothelioma, lung, laryngeal, and ovarian cancers. All forms of asbestos may cause gastrointestinal and other cancers. ${ }^{2}$

Asbestos was declared a proven human carcinogen by the US Environmental Protection Agency (EPA), the International Agency for Research on Cancer (IARC) of the World Health Organization, and the National Toxicology Program (NTP) more than 20 years ago. ${ }^{3-5)}$ The scientific community is in overwhelming agreement that there is no safe 
level of exposure to asbestos. $\left.{ }^{6}\right)$ Moreover, there is no evidence of a threshold level below which there is no risk of mesothelioma. ${ }^{\text {) }}$

\section{The Asbestos Cancer Pandemic}

\section{Occupational Exposures to Asbestos}

About 125 million people around the world are exposed to asbestos in their work environments, ${ }^{8)}$ and many millions more workers have been exposed to asbestos in years past. About 20-40 percent of adult men report having worked in occupations that may have entailed asbestos exposures. ${ }^{9}$ ) In the most highly affected age groups, mesothelioma may account for over $1 \%$ of all deaths. ${ }^{10,11)}$ In addition to mesothelioma, 5-7 percent of all lung cancers are potentially attributable to occupational exposures to asbestos. ${ }^{12)}$

Worldwide, the yearly number of asbestosrelated cancer deaths in workers is estimated to be 100,000-140,000. In Western Europe, North America, Japan, and Australia 20,000 new cases of lung cancer and 10,000 cases of mesothelioma result every year from exposures to asbestos. ${ }^{13)}$ In the United Kingdom at least 3,500 people die from asbestos-related illnesses each year, and this number is expected to increase to 5,000 in future years. ${ }^{8)}$ The British mesothelioma death-rate is now the highest in the world, with 1,740 deaths in men ( 1 in 40 of all male cancer deaths below age 80 ) and 316 in women in 2006. About 1 in 170 of all British men born in the 1940s will die of mesothelioma. $^{13)}$ Australia's high incidence of mesothelioma is expected to reach 18,000 by 2020 , with 11,000 cases yet to appear. ${ }^{14)}$

The US National Institute for Occupational Safety and Health (NIOSH) estimates that current occupational exposures to asbestos even at OSHA's permissible exposure limit will cause 5 deaths from lung cancer and 2 deaths from asbestosis in every 1,000 workers exposed for a working lifetime. ${ }^{15)}$

\section{Non-occupational Exposures to Asbestos}

Non-occupational, environmental exposure to asbestos from the use of asbestos in construction materials is a serious and often neglected problem in countries throughout the world. In developed countries large quantities of asbestos are found today as a legacy of past construction practices in many thousands of schools, homes, and commercial buildings. And in developing countries, where asbestos continues to be used in large quantities in construction, asbestos-contaminated dust is now accumulating in thousands of communities.

More than 90 percent of the asbestos used worldwide today is used in the manufacture of asbestos-cement sheets and pipes, and most of this material is used in developing countries. Use of asbestos in these materials continues despite repeated warnings that the use of asbestos in these products is highly dangerous because of the large numbers of people exposed to the airborne dust and the extreme difficulty of controlling exposures once these materials have been disseminated into communities where people of all ages, including young children, are at risk of exposure. ${ }^{16)} \mathrm{A}$ pervasive problem with use of asbestos-containing materials in construction is that asbestos fibers are released to air and dust as these materials weather, erode, break or are cut by saws and other power tools. ${ }^{8)}$ Community-wide exposure to persons of all ages is the end result.

Both community-based and industrial exposures to asbestos and asbestiform fibers increase risks for mesothelioma. ${ }^{17)}$ Thus a study of women residing in Canadian asbestos mining communities found a sevenfold increase in the mortality rate from pleural cancer. ${ }^{18)}$ The risk of developing asbestos-related cancer following in-home exposures in communities near Canadian mines over a 30 year period is estimated to be 1 in $10,000 .{ }^{19)}$ Likewise, environmental exposures to asbestos waste on the surfaces of roads and yards in a contaminated community of 130,000 residents in The Netherlands result each year in several cases of malignant mesothelioma. ${ }^{20)}$ And in a third example, the currently observed increase in female cases of mesothelioma in the United Kingdom, many with no occupational exposure to asbestos, suggests widespread environmental contamination. ${ }^{11)}$

\section{Chrysotile Asbestos}

Chrysotile represents 95 percent of all the asbestos ever used worldwide. It is the only variety in international trade in the $21^{\text {st }}$ century. 
There is general agreement among scientists and physicians, and widespread support from numerous national health agencies in countries around the world, United Nations agencies, and the World Trade Organization, that chrysotile causes various cancers, including mesothelioma and lung cancer. ${ }^{21-30}$

Early suggestions that chrysotile might be less dangerous than other forms of asbestos have not been substantiated. Although chrysotile accounts for almost all the asbestos ever used, the asbestos industry continues to claim that asbestos-related cancers are the result of the amphibole varieties. ${ }^{31,32)}$ Consultant experts of the Canadian chrysotile asbestos industry contend - falsely, and despite all of the abundant medical and scientific evidence to the contrary - that "Exposure to chrysotile in a pure form seems likely to present a very low if any risk of mesothelioma." ${ }^{\text {33) }}$

The Chrysotile Institute, a registered lobby group for the Quebec asbestos mining industry, takes the position that chrysotile can be handled safely. ${ }^{34)}$ But refuting this scientifically untenable and highly misleading position are numerous epidemiologic studies, case reports, controlled animal experiments, and toxicological studies which show clearly and consistently that chrysotile is highly dangerous and that it is fully capable of causing cancer. ${ }^{13,35-40)}$ These studies demonstrate that the so-called "controlled use" of asbestos is a fallacy. ${ }^{41,42)}$ Workers exposed to chrysotile fiber alone have excessive risks of lung cancer and excessive deaths from mesothelioma. ${ }^{43-45)}$

The Canadian Medical Association, the Canadian Cancer Society, and Canada's leading health experts oppose the export of asbestos to developing countries. The National Public Health Institute of Quebec (INSPQ) has published fifteen reports, all of them showing a failure to achieve "controlled use" of asbestos in Quebec itself. Pat Martin, a member of Canada's parliament and former asbestos miner asks, "If we in the developed world haven't found a way to handle chrysotile safely, how can we expect them to do so in developing nations?"46)

\section{Current Production and Use of Asbestos}

Despite all that is known about the health effects of asbestos, annual world production remains at over 2 million tons. This level of production has remained steady following a $50 \%$ decline in the 1990s. Russia is now the leading producer of asbestos worldwide, followed by China, Kazakhstan, Brazil, Canada, Zimbabwe, and Colombia. These six countries accounted for $96 \%$ of the world production of asbestos in 2007. ${ }^{47)}$ Russia has mines rich enough in asbestos deposits to last for more than 100 years at current levels of production. The majority of the 925,000 tons of asbestos extracted annually in Russia is exported.

Asbestos is now banned in 52 countries, including all EU member countries, and safer products have replaced many that were once made with asbestos. Virtually all of the polymeric and cellulose fibers used instead of asbestos in fiber-cement sheets are greater than 10 microns in diameter and hence are non-respirable. Nonetheless, these 52 countries make up less than a third of WHO member countries.

Unfortunately, a much larger number of WHO member countries still use, import, and export asbestos and asbestos-containing products. $^{30)}$ These are mostly developing countries, and over 70 percent of the world production of asbestos is used today in Asia and Eastern Europe, in countries desperate for industrial growth and often naïve to the health effects of occupational and environmental exposures to asbestos. A recent article in The Lancet notes that "Vast development projects in Asia are largely responsible for maintaining the [chrysotile asbestos] market. In particular, India's asbestos industry is burgeoning."46)

In many countries that have banned other forms of asbestos, the "controlled use" of chrysotile asbestos is still permitted, despite all medical and scientific information to the contrary. This exemption reflects the size of the asbestos industry, its pervasive influence, and the importance of asbestos mining and manufacture to the economy. The toll in most countries still using large amounts of asbestos may never be fully recorded.

In developing countries, where too often there exists little or no protection of workers and communities, the asbestos cancer pandemic may be the most devastating. China is by far the largest consumer of asbestos in the world today, followed by India, Russia, Kazakhstan, Thailand, Ukraine, 
and Uzbekistan.

\section{Position of United Nations Agencies on Asbestos}

International organizations have condemned the continuing use of chrysotile asbestos. ${ }^{48)}$ In 2006, WHO called for the elimination of diseases associated with asbestos. ${ }^{30)} \mathrm{WHO}$ supports individual countries in developing national plans to ban asbestos and eliminate asbestos-related diseases. WHO has stated that "the most efficient way to eliminate asbestos-related disease is to stop using all types of asbestos."

The ILO has expressed concern about an evolving epidemic of asbestos-related diseases, and passed a resolution to promote a worldwide asbestos ban. ${ }^{24)}$

The World Trade Organization has accepted the conclusion that the so-called "controlled use" of asbestos is a fallacy. ${ }^{49}$

The Rotterdam Convention is an international treaty intended to regulate global trade in dangerous chemicals - chemicals that have been banned or severely restricted because of their hazards to human health or the environment. It was enacted in 2004, and 131 nations are currently parties to the Convention. The goal is to protect the world's most vulnerable countries - developing countries and countries with economies in transition - against importation without their prior knowledge or consent of hazardous pesticides and other regulated chemicals.

Prior Informed Consent (PIC) is the core principle of the Rotterdam Convention. This legally binding procedure requires that governments in all countries be provided full information prior to importation about the risks to health and the environment of each of the hazardous materials regulated by the Convention. Annex III of the Rotterdam Convention contains a list of the chemicals - 37 in number - currently regulated by the Convention.

Repeated efforts to include chrysotile asbestos under the Rotterdam Convention have failed, because of the Convention's requirement for unanimity and the determined opposition of asbestos mining and manufacturing countries. ${ }^{50)}$ At the 2008 conference of parties on the Convention, opposition to chrysotile asbestos was led by Canada, Russia, and India. Kazakhstan and a few asbestos importing countries thwarted the will of over 100 other countries.

\section{The Need for a Universal Ban on Asbestos}

The profound tragedy of the asbestos pandemic is that virtually all illnesses and deaths related to asbestos are preventable. Safer substitutes for asbestos exist, and they have been introduced successfully in many nations. Asbestos-cement (A-C) pipes, sheets, and water storage tanks account for 90 percent of asbestos used in the world today. Substitutes for A-C water pipe include ductile iron pipe, high-density polyethylene pipe, and metal-wire-reinforced concrete pipe. Many substitutes exist for roofing, interior building walls and ceilings, including fiber-cement flat and corrugated sheet products, made with polyvinyl alcohol fibers and cellulose fibers. For roofing, lightweight concrete tiles can be made and used in the most remote locations, using locally available plant fibers including jute, hemp, sisal, palm nut, coconut coir, and wood pulp. Galvanized iron roofing and clay tiles are among the other alternative materials. ${ }^{51)}$

If global use of asbestos were to cease today, a decrease in the incidence of asbestos-related diseases would become evident only two or more decades from now. ${ }^{30)}$ This delay is a consequence of the long latency period associated with the diseases caused by asbestos. In the case of mesothelioma, the latency between exposure and disease may be as long as 40-50 years.

The asbestos cancer pandemic may take as many as 10 million lives before asbestos is banned worldwide and all exposure is brought to an end. ${ }^{48,52)}$ In this conservative estimate, it is assumed that asbestos exposures are going to cease and that the epidemic will run itself out. But in fact, the world's current production of asbestos continues at an alarming rate, and therefore these figures may be underestimates of the true reality of this pandemic.

An international ban on the mining and use of asbestos is urgently needed. The risks of exposure to asbestos cannot be controlled by technology or by regulation of work practices. Scientists and 
responsible authorities in countries allowing the use of asbestos should have no illusion that "controlled use" of chrysotile asbestos is an effective alternative to a ban on all use of asbestos. ${ }^{53,54)}$ Even the best workplace controls cannot prevent occupational and environmental exposures to products in use or to waste. Safer substitute products are available and in use in countries all over the world where asbestos is banned.

To protect the health of all people in the world industrial workers, construction workers, women and children, now and in future generations - the Collegium Ramazzini calls again today on all countries of the world, as we have repeatedly in the past, to join in the international endeavor to ban all forms of asbestos. An international ban on asbestos is urgently needed.

\section{References}

1. Collegium Ramazzini : Call for an international ban on asbestos. Journal of Occupational and Environmental Medicine, 41(10), 830-832, 1999.

2. Straif, K., Benbrahim-Tallaa, L., Baan, R., Grosse, Y., Secretan, B., El Ghissassi, F., Bouvard, V., Guha, N., Freeman, C., Galichet, L. and Cogliano, V. : WHO International Agency for Research on Cancer Monograph Working Group. A review of human carcinogens--part C: metals, arsenic, dusts, and fibres. Lancet Oncology, 10(5), 453-454, 2009.

3. EPA (Environmental Protection Agency). Airborne Asbestos Health Assessment Update. EPA/6000/884/003E, EPA, Washington, D.C., June, 1986.

4. IARC (International Agency for Research on Cancer). Asbestos: Monograph on the Evaluation of Carcinogenic Risk to Man. Vol. 14. Lyon, France: IARC, 1977.

5. NTP (National Toxicology Program). Report on Carcinogens, 1ST ed. U.S. Department of Health and Human Services, Public Health Service, 1980.

6. Welch, L. S. : Asbestos exposure causes mesothelioma, but not this asbestos exposure: An amicus brief to the Michigan Supreme Court. International Journal of Occupational and Environmental Health, 13, 318-327, 2007.

7. Hillerdal, G. : Mesothelioma: cases associated with non-occupational and low dose exposures. Occupational and Environmental Medicine, 56(8), 505513, 1999.

8. Egilman, D., Fehnel, C. and Bohme, S. R. : Exposing the "myth" of ABC, "anything but chrysotile": a critique of the Canadian asbestos mining industry and McGill University chrysotile studies. Occupational and Environmental Medicine, 44, 540-557,
2003

9. Goldberg, M., Banaei, A., Goldberg, S., Anvert, B., Luce, D. and Gueguen, A. : Past occupational exposure to asbestos among men in France. Scandinavian Journal of Work, Environment and Health, 26, 52-61, 2000.

10. Driscoll, T., Nelson, D. I., Steenland, K., Leigh, J., Concha-Barrientos, M. and Fingerhut, M. : The global burden of disease due to occupational carcinogens. Ammerican Journal of Industrial Medicine, 48(6), 419-431, 2005.

11. Rake, C., Gilham, C., Hatch, J., Darnton, A., Hodgson, J. and Peto, J. : Occupational, domestic and environmental mesothelioma risks in the British population: a case-control study. British Journal of Cancer, 100(7), 1175-1183, 2009.

12. Tossavainen, A. : Global use of asbestos and incidence of mesothelioma. International Journal of Occupational and Environmental Health, 10, 2225, 2004.

13. Tossavainen, A. : Asbestos, asbestosis and cancer: the Helsinki criteria for diagnosis and attribution. Consensus report. Scandinavian Journal of Work, Environment and Health, 23, 311-316, 1997.

14. Leigh, J. and Driscoll, T. : Malignant mesothelioma in Australia, 1945-2002. International Journal of Occupational and Environmental Health, 9(3), 206217, 2003.

15. Stayner, L., Smith, R., Bailer, J., Gilbert, S., Steenland, K., Dement, J., Brown, D. and Lemen, R. : Exposure-response analysis of risk of respiratory disease associated with occupational exposure to chrysotile asbestos. Occupational and Environmental Medicine, 54, 646-652, 1997.

16. WHO (World Health Organization). Environmental Health Critera 203: Chrysotile Asbestos. Geneva, Switzerland: WHO, 1998.

17. Pasetto, R., Comba, P. and Marconi, A. : Mesothelioma associated with environmental exposures. Medicina Lavora, 96(4), 330-337, 2005.

18. Camus, M., Siemiatycki, J. and Meek, B. : Nonoccupational exposure to chrysotile asbestos and the risk of lung cancer. New England Journal of Medicine, 338, 1565-1571, 1998.

19. Marier, M., Charney, W., Rousseau, R., Lanthier, R., Van Raalte, J. : Exploratory sampling of asbestos in residences near Thetford Mines: The public health threat in Quebec. International Journal of Occupational and Environmental Health, 13, 386397, 2007.

20. Driece, H. A., Siesling, S., Swuste, P. H. and Burdorf, A. : Assessment of cancer risks due to environmental exposure to asbestos. Journal of Experimental Science and Environmental Epidemiology, 2009; in press.

21. ACGIH (American Conference of Governmental Industrial Hygienists). Asbestos: TLV Chemical Substances $7^{\text {th }}$ Edition Documentation. Publication 
\#7DOC-040. Cincinnati OH: ACGIH, 2001.

22. ATSDR (Agency for Toxic Substances and Disease Registry). Toxicological Profile for Asbestos. U.S. Department of Health and Human Services, Atlanta, GA, 2001.

23. ILO (International Labour Organization). ILO adopts new measures on occupational safety and health, the employment relationship, asbestos. International Labour Organization, 2006. http:// www.ilo.org/public/english/bureau/inf/pr/2006/34. htm

24. ISSA (International Social Security Association). Déclaration sur l'amiante, Pékin, Septembre 16, 2004.

25. NTP (National Toxicology Program). Report on Carcinogens, 11th ed. U.S. Department of Health and Human Services, Public Health Service, 2004.

26. NCI (National Cancer Institute). Factsheet-Asbestos: Questions and Answers. Bethesda, MD: National Institutes of Health, 2003.

27. OSHA (Occupational Safety and Health Administration). Occupational exposure to asbestos: Final rule. Federal Register, 59, 40964-41162, 1994.

28. UNEP (United Nations Environment Program), ILO (International Labor Office), WHO (World Health Organization). Chrysotile Asbestos, Environmental Health Criteria 203. Geneva, Switzerland: WHO, 1998.

29. WHO (World Health Organization). Elimination of Asbestos Related Diseases. Geneva, Switzerland: WHO, 2006.

30. WTO (World Trade Organization). European Communities-Measures Affecting Asbestos and Asbestos-containing Products. WT/DS135/R. 2000.

31. McCulloch, J. : Saving the asbestos industry, 1960 to 2006. Public Health Reports, 121, 609-614, 2006.

32. Renner, R. : Chrysotile on ice. Enviromental Health Perspectives, 115(3), 130, 2007.

33. Gibbs, G. W. and Berry, G. : Mesothelioma and asbestos. Regul Toxicol Pharmacol, 52(1 Suppl), S223-31, 2008

34. Chrysotile Institute. The crusade against chrysotile must end. Newsletter. 7(2), 2, 2008. http://www. chrysotile.com/data/newsletter/Chrysotile_Dec2008_ EN.pdf

35. Bang, K. M., Pinheiro, G. A., Wood, J. M. and Syamlal, G. : Malignant mesotheilioma mortality in the United States, 1999-2001. International Journal of Occupational and Environmental Health, 12(1), $2-15,2006$

36. Landrigan, P., Nicholson, W. J., Suzuki, Y. and LaDou, J. : The hazards of chrysotile asbestos: a critical review. Industrial Health, 37, 271-280, 1999.

37. Lemen, R. A. : Chrysotile asbestos as a cause of mesothelioma: Application of the Hill causation model. International Journal of Occupational and
Environmental Health, 10, 233-239, 2004a.

38. Lin, R. T., Takahashi, K., Karjalainen, A., Wilson, D., Kameda, T., Chan, C. C., Wen, C. P., Furuva, S., Higashi, T., Chan, L. C. and Ohtaki, M. : Ecological association between asbestos-related diseases and historical asbestos consumption: an international analysis. The Lancet, 20(9564), 844849, 2007.

39. Smith, A. H. and Wright, C. C. : Chrysotile asbestos is the main cause of pleural mesothelioma. American Journal of Industrial Medicine, 30, 252266, 2006.

40. Stayner, L. T., Dankovic, D. A. and Lemen, R. A. : Occupational exposure to chrysotile asbestos and cancer risk: A review of the amphibole hypothesis. American Journal of Public Health, 86, 179-186, 1996.

41. Lemen, R. A. : Asbestos in brakes: exposure and risk of disease. American Journal of Industrial Medicine, 45(3), 229-237, 2004b. Review.

42. Castleman, B. : WTO confidential: The case of asbestos. International Journal of Health Services, 32, 489-501, 2002

43. Frank, A. L., Dodson, R. F. and Williams, M. G. : Carcinogenic implications of the lack of tremolite in UICC reference chrysotile. American Journal of Industrial Medicine, 34, 314-317, 1998.

44. Li, L., Sun, T. D., Zhang, X., Lai, R. N., Li, S. Y., Fan, X. J. and Morinaga, K. : Cohort studies on cancer mortality among workers exposed only to chrysotile asbestos: a meta-analysis. Biomedicine and Environmental Science, 17(4), 459-468, 2004.

45. Mirabelli, D., Calisti, R., Barone-Adesi, F., Fornero, E., Merletti, F. and Magnani, C. : Excess of mesotheliomas alter exposure to chrystoile in Balangero, Italy. Occupational and Environmental Medicine, 65(12), 815-819, 2008.

46. Burki, T. : Health experts concerned over India's asbestos industry. The Lancet, $\mathbf{3 7 5}(9715)$, 626-627, 2010. http://www.thelancet.com/journals/lancet/ article/PIIS0140-6736(10)60251-6/fulltext

47. USGS (U.S. Geological Survey). U.S. Department of the Interior. 2008 Minerals Yearbook, Volume I.- Metals and Minerals. Asbestos, 2008. http://minerals.usgs.gov/minerals/pubs/commodity/asbestos/ index.html\#myb

48. LaDou. J. : The asbestos cancer epidemic. Environmental Health Perspectives, 112, 285-290, 2004.

49. WBG (World Bank Group). Good Practice Note: Asbestos: Occupational and Community Health Issues, May 2009. http://siteresources.worldbank. org/EXTPOPS/Resources/AsbestosGuidanceNoteFinal.pdf

50. Terracini, B. : Rotterdam Convention: Chrysotile is still in the waiting list. Epidemiologia e Prevenzione, 32(6), 275-276, 2008.

51. WBG (World Bank Group). Good Practice Note: 
Asbestos: Occupational and Community Health Issues, May 2009. http://siteresources.worldbank. org/EXTPOPS/Resources/AsbestosGuidanceNoteFinal.pdf

52. Leigh, J. : Asbestos-related diseases: International estimates of future liability. Abstract. 5th International Congress on Work Injuries Prevention, Rehabilitation and Compensation \& 2nd Australian
National Workers Compensation Symposium (1821 March, 2001, Adelaide, Australia).

53. Castleman, B. : "Controlled use" of asbestos. International Journal of Occupational and Environmental Health, 9, 294-298, 2003.

54. Egilman, D. and Roberts, M. : Controlled use of asbestos. International Journal of Occupational and Environmental Health, 10, 99-103, 2004. 